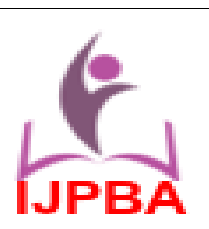

\author{
Contents lists available at www.ijpba.in \\ International Journal of Pharmaceutical and Biological Science Archive \\ PubMed (National Library of Medicine ID: 101738825) \\ Index Copernicus Value 2017: 71.80
}

Volume 7 Issue 2; March-April; 2019; Page No. 263-266

\title{
A REVIEW ON PHARMACOLOGICAL ACTIVITY OF BENINCASA HISPIDA
}

\author{
Neha Ayubkhan ${ }^{1 *}$, Dr Mathew George ${ }^{1}$, Dr Lincy Joseph ${ }^{2}$, Dr K Sujith ${ }^{1}$ \\ ${ }^{1}$ Department of Pharmacology, Pushpagiri College of Pharmacy, Thiruvalla-689107, Kerala, India \\ ${ }^{2}$ Department of Pharmaceutical Chemistry, Pushpagiri College of Pharmacy, Thiruvalla-689107, \\ Kerala, India
}

\begin{abstract}
Benincasa hispida is a well-known plant and is cultivated throughout the plains of india and on the hills upto 1200 meter altitude. It is a popular vegetable crop widely used for nutritional and medicinal properties especially in asian countries. Benincasa hispida fruit has been valued as a nutritious vegetable as it provide a good source for natural sugars,organic acid, amino acid,vitamins and mineral elements. Phytochemical constituents of this plant are mannitol, triterpenoids, cucurbitin, $\beta$-sitosterin, flavanoids, glycosides, carotenes, vitamins and uronic acid. The pharmacological studies revealed that the plant exerted many pharmacological activities such as antiulcer, antihyperlipidemic, antihelmintic, antioxidant, neuropharmacological activity, diuretic activity.
\end{abstract}

Keywords: Benincasa hispida, antiulcer, diuretic, antihyperlipidemic, antihelminthic.

\section{INTRODUCTION}

Benincasa hispida which belongs to the family cucurbitaceae commonly called wax gourd, ash gourd, winter melon. Wax gourd has been used as a food and medicine for thousand of years in east asia. All parts of the plant are used medicinally. This plant grows annually. This plant is a creeping with branched tendrils that can climb over with the help of some support,cover fences or sprawl along the ground. Stems are thick, hairy, grooved conspicuously and lined with sharp bristles. Leaves are round, kidney shaped with upper rough surface. These have beautiful flower of golden yellow colour. Fruits contain numerous white coloured embedded seeds. ${ }^{[8]}$

In ayurvedic medicines, seeds are used in the treatment of antihelmintic, anti-inflammatory demulcent, diuretic, expectorant, laxative and tonic. Fruit are diuretic, laxative, tonic. It is used in ayurvedic medicine in the treatment of epilepsy, lung disease, asthma and cough. Fruit juice is used in the treatment of insanity, epilepsy and other nervous disease. This plant has been used in the form of taila, rasayana in the siddha system of medicines.

Phytochemical constituents of this plant are mannitol, triterpenoids, cucurbitin, $\beta$-sitosterin, flavanoids, glycosides, carotenes, vitamins and uronic acid. ${ }^{[7]}$

\section{Scientific Classification:}

Kingdom - Plantae

Clade - Angiosperms

Clade - Eudicots

Order - Cucurbitales

Family-Cucurbitaceae

Genus - Benincasa

Species - B. Hispida

Botanical Name: Benincasa Hispida

Common Name:

English - Ash gourd, Wax gourd, White gourd, Winter melon, Fuzzy melon, Hairy melon.

Sanskrit - Kushmanda, Pushpaphala, Pitaphushpa, Karkaru. 
Hindi - Petha, Pethakaddu.

Tamil - Neer poosanikai.

Malayalam - Kumbalam, Kumbalanga.

Telugu - Boodida gummadikaaya.

Kannada - Boodu gumbala, Budekumbalakayi.

\section{LITERATURE REVIEW}

Jayasree Thirumalashetty et al (2013) evaluated diuretic activity of ethanolic extract of benincasa hispida stem in swiss albino rat in comparison with standard drug hydrochlorthiazide. The animals were divided into five different groups. The first group was kept as control (Normal Saline), second as the standard (Hydro chlorthiazide) and the remaining three groups as Test I, Test II, and Test III and given different doses of ethanolic extract of benincasa hispida. Diuretic activity and natriuretic activity was carried out by the administration of normal saline along with the treatment modules. The volume of urine (in $\mathrm{ml}$ ) and therefore the $\mathrm{Na}^{+}, \mathrm{K}^{+}$and $\mathrm{Cl}^{-}$content in the urine were measured. It shows significant diuresis and increased sodium elimination but not potassium. Thus the study elucidates that ethanolic extract of benincasa hispida stem possess significant diuretic, saluretic, natriuretic, carbonicanhydrase activity. ${ }^{[5]}$

Gokul Durairaj et al (2015) evaluated neuropharmacological activities of methanolic extract of benincasa hispida in mice. The methods used are Forced swim test (FST) and Tail suspension Test (TST). Study was found to have reduction of uncharacterized CNS depression in various neurological animal models. The most outstanding being the antidepressant activity in forced swim test. While exploring the anti-anxiety profile of the extract in open field test in mice and social interaction test in rats, the results were inconclusive indicating to some degree of anxiogenic or no antianxiety result in these models that is true to certain antidepressants used clinically. The extract in marble burying test revealed the potential use in neurotic compulsive disorders. Thus it reveals a wide spectrum of neuropharmacological activities of benincasa hispida in mice. ${ }^{[3]}$

Manish A Rachchh et al (2008) evaluated antiulcer activities of benincasa hispida fruit extract in rats against ethanol-induced gastric mucosal damage, pylorus ligated ( $\mathrm{PL}$ ) gastric ulcers, and cold restraint-stress (CRS)-induced gastric ulcer models. Petroleum ether and methanol extracts were administrated orally and omeprazole (standard) was administrated orally. Ulcer index was common parameter studied altogether the models. Further, vascular permeability was evaluated in ethanol model, and effect on lipid peroxidation, melondialdehyde (MDA) content, superoxide dismutase (SOD), and catalase (CAT) levels were studied in CRS model. Both the extracts produced significant reduction in ulcer index in all the models and the results were comparable with that of omeprazole-treated group. Further, significant reduction in vascular permeability was observed. In CRS model, MDA content was significantly reduced along with increase in CAT levels as compared to control group. Thus Petroleum ether and methanol extracts of $B$. hispida possess significant antiulcer also a inhibitor property. ${ }^{[4]}$

Krishna Mohan Chinnala et al (2016) evaluated absolute ethanolic extract of Benincasa hispida for its antihyperlipidemic effect and antiobesity activity in olive oil induced Wistar albino rats. Normal and olive oil induced hyperlipidemic rats were pretreated with single daily administration of distill water, simvasatin, $200 \mathrm{mg} / \mathrm{kg}$ and $400 \mathrm{mg} / \mathrm{kg}$ Benincasa hispida fruit extract orally, for 28 days for every 24 hours in each group (II, III, IV and V) except control. The activity was assessed by estimation of body weight, liver weight, food intake, serum lipid profile. The bio chemical parameters like Total cholesterol (TC), Triglycerides (TG), High density lipoprotein cholesterol (HDL-C), Low density lipoprotein cholesterol (LDL-C), Very low density lipoprotein cholesterol (VLDL-C), atherogenic index, Blood glucose levels and histopathology of liver were conjointly assessed. The stratified 
doses of Benincasa hispida extract significantly reduced the weight gain pattern of body and liver and causes dose related reduction in serum lipids, atherogenic index and glucose. The study demonstrated that Benincasa hispida extract shows both antihyperlipidemic and antiobesity effects, which may be partly mediated by anorectic effect, probably through CNS mediation, with no effect on gastric emptying, and inhibition of denovo biosynthesis of cholesterol. ${ }^{[2]}$

Chiranjib Bhattacharjee et al (2010) evaluated antihelmintic activities of crude aqueous, Petroleum ether, chloroform and Methanol extract of Benincasa hispida leaves using Pheretima posthuma as test worms. Single concentration ( $5 \%$ ) of extracts was tested within the bioassay, which involved determination of time of paralysis $(P)$ and time of death (D) of the worms. Piperazine citrate was included as standard reference and distilled water as control. The results of the study indicated that Benincasa hispida leaves extracts were exhibited anthelmintic activity significantly compared with standard (Piperazine citrate) group. Chloroform extract and petroleum ether extract showed shortest time of paralysis (P) and death (D) with 50 $\mathrm{mg} / \mathrm{ml}$ concentration respectively among all extracts. Whereas, in control group, worms were observed for 24 hours and no paralysis or death was found during that period. Thus, crude aqueous, petroleum ether, chloroform and methanol extract of benincasa hispida shows antihelminthic activity. ${ }^{[6]}$

Shristi Badhani et al (2013) evaluated antioxidant activity of ethanolic and aqueous extract of Benincasa hispida (Thunb) Cogn fruit for their therapeutic potential. Invitro antioxidant activity was performed by 1,1 diphenyl-2-picrylhydrazyl (DPPH) and Hydrogen peroxide $\left(\mathrm{H}_{2} \mathrm{O}_{2}\right)$. For aqueous extract the scavenging activity of DPPH is $59.7 \%$ at the concentration of $200 \mu \mathrm{g} / \mathrm{ml}$ and the activity of $\mathrm{H}_{2} \mathrm{O}_{2}$ is $20.5 \%$ at concentration of $1000 \mu \mathrm{g} / \mathrm{ml}$. For ethanolic extract the scavenging activity of $\mathrm{DPPH}$ is $77.4 \%$ at the concentration of 250 $\mu \mathrm{g} / \mathrm{ml}$ and the activity of $\mathrm{H}_{2} \mathrm{O}_{2}$ is $21.3 \%$ at concentration of $1000 \mu \mathrm{g} / \mathrm{ml}$. The method is compared to standard (ascorbic acid). Presence of phytochemicals like carbohydrates, proteins and amino acids, flavonoids, phenolic compounds might contribute to observed antioxidant activity. Benincasa hispida fruits are potential source of natural antioxidant compounds to replace synthetic antioxidants. It was found that higher amount antioxidant activity was obtained in the ethanol.

Thus, ethanolic extract of Benincasa hispida (Thunb) Cogn fruit can be used to treat diseases caused by free radicals and oxidative stress. $^{[1]}$

\section{CONCLUSION}

On the basis of these investigations, we may conclude that Benincasa hispida shows antiulcer activity, diuretic activity, neuropharmacological activity, antioxidant activity, antihelminthic activity, antihyperlipidemic and antiobesity activities in animal model. There is increasing demand for the herbal medicinal plants all over the world because the fact that the allopathic drugs are having more side effects and this is one of the herbal drug having numerous actions to cure differing types of diseases.

\section{REFERENCE}

1. Shristi Badhani, Amrita Kainth, Atul Kabra, Bharat Parashar; Evaluation of Antioxidant Activity of Benincasa hispida Fruit Extracts; American Journal of Pharmtech Research; 2013;3(2):335-345.

2. Krishna Mohan Chinnala, Madhan Mohan Elsani, Santhosh Sarvu; Antihyperlipidemic and antiobesity activity of ethanolic extract of Benincasa hispida fruits on hyperlipidemic rats; World Journal of Pharmaceutical Sciences;2016;4(3):363371.

3. Gokul Durairaj and Kirubanandan Shanmugam; Evaluation of NeuroPharmacological Activities of Methanolic Extract of Benincasa hispida; International Journal of Pharmaceutical and Journal Sciences;2015;4(3):410-421. 
'Neha Ayubkhan et al, Journal of Pharmaceutical and Biological Science Archive

4. Manish A. Rachchh, Sunita M. Jain; Gastroprotective effect of Benincasa hispida fruit extract; Indian Journal Pharmacology;2008;40(6):271-275.

5. Jayasree Tirumalasetty, Chandrasekhar. N and A. Naveen; Evaluation of diuretic activity of ethanol extract of Benincasa hispida stem in swiss albino rats; Journal of Chemical and Pharmaceutical Research; 2013;5(3):91-97.

6. Chiranjib Bhattacharjee,Debjit B, Pankaj Tiwari, K K Tripathi, A S Dutta; Invitro Antihelminthic activity of Benincasa

hispida; International Journal of Pharma and Bio Sciences;2010;1(2):1-5.

7. Kuntal Ghosh, M S Baghel; Pharmacognostical and Physicochemical Study of Benincasa hispida with Ayurvedic Review; International Journal of Research in Ayurveda and Pharmacy;2011;2(6):16641668.

8. $\operatorname{Dr} V$ B Washimkar, $\operatorname{Dr} M$ B Shende; Kushmanda with brief uses and its Ingredients; European Journal of Pharmaceutical and Medicinal Research; 2016;3(9):158-162. 